\title{
Unable to Obtain Readings
}

National Cancer Institute

\section{Source}

National Cancer Institute. Unable to Obtain Readings. NCI Thesaurus. Code C62826.

The device does not provide or display a valid reading. 